\title{
ON THE OCCURRENCE OF \\ MASSIVE CHOLESTERIN DEPOSITS IN THE BREAST IN CASES OF LONG-STANDING MASTITIS.
}

\author{
BY MATTHEW J. STEWART, LEEDS, \\ AND J. A. CAIRNS FORSYTH, London.
}

Cirolesterin in crystalline form may be deposited in the tissues in many situations and as a result of divers pathological processes. In most cases the crystals make their appearance in consequence of local tissue disintegration, whether from necrosis or from the retention of inflammatory exudates or effused blood. In certain situations, such as the breast, an additional possible factor is the retention of secretory products which results from duct obstruction.

The tabular form of cholesterin is most frequently met with, giving rise to the wellknown appearance of clefts in paraffin sections ; less often the acicular crystalline form is assumed. When the crystals are deposited in, or come to be surrounded by, living connective tissue, they stimulate the formation of a very special cellular reaction round about, in which foreign-body giant cells and endothelial cells with foamy cytoplasm form the most prominent feature.

In the breast, certain forms of subacute inflammation with retention of the secretions have been found to be associated with the deposition of cholesterin crystals, mainly of the acicular type. These occur within the lumen of the inflamed and dilated ducts, and when once the epithelial lining has been shed, they become surrounded by a complete ring of foreign-body giant cells, from which fine cytoplasmic processes run inwards between the individual crystals. These giant-cell rosettes are highly characteristic structures as seen in paraffin sections, and may be present in quite considerable numbers. In a few instances plate cholesterin has also been demonstrated amongst the inflammatory tissue.

The total amount of cholesterin present in the breast in such circumstances is usually quite small, but, exceptionally, very large quantities may be deposited. The writers have had the opportunity of studying two such cases, the details of which follow :-

Case 1.-(1803.)

Clinical History.- The patient, a woman, age 63 , gave the following history. She was married in 1860 at the age of 19 , and her first child was born ten months later. Her second and only other child was born nine years after the first. In the interval she had a miscarriage, and she also had an abscess of the left breast, which, however, had quite recovered by the time the second child was born. Both her children were suckled on both breasts. In 1898, ten years before ndmission to hospital, she received a blow on the left breast. Thereafter, a small, hard lump made its appearance in the breast and slowly increased in size, while latterly the nipple discharged blood and 'matter' from time to time. Towards the end of 1902 there was a rupid increase in the size of the tumour, which became also less mobile and very painful, while the skin over it became inflamed.

ON ADmission to hospitul on January 10, 1903, the breast was very much enlarged and inflamed. Parts of the tumour were hard and nodular, but in the centre near the nipple it was soft and fluctuating. The skin here was stretched and shining, and of a dark-purple colour, and on the day following admission it ruptured, allowing the escape of a large quantity of glistening. blood-stained serous fluid. There still remained within the cavity a soft, jelly-like, semifluctuant material, which gradually disappeared in the course of the day, leaving the cavity lined by what were thought to be sprouting granulations. No enlarged glands could be felt in the axilla. The breast was amputated one month later. 
Description of SPLCiMen (Fig. 28),-The breast contains a number of cysts measuring fron $\frac{1}{2}$ in. to 2 in. in diameter, with thick fibrous walls. Two of the largest communicate by wide apertures with the surface. The cysts in every instance show a number of white, cauliflower-like nodules of tumour-tissue sprouting from their walls, and in three the entire space is orcupied by these masses of growth. Otherwise the eyst walls are perfectly smooth

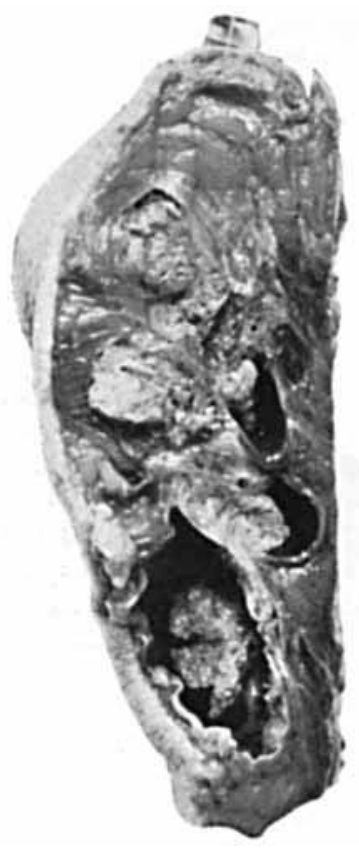

lile. 2x. Case 1. Slice from the centre of the breint, showin: cyst; with papilliferous caleinomatous musces sprouting from the walls. The cholestrem the ring portions are terin-bearing portions are tije solin chark areats adiacent to
the eysts. inside, and on transverse section they show a narrow inner layer of white fibrous tissue, and an outer brouder zone of a rich-brown colour, due to the presence of iron-containing pigment. Immediately adjacent to some of the cysts there are circumscribed solid areas, showing a mixture of the same richred tissue with yellowish, glistening patrhes of cholesterin and lipoid deposit.

The whole breast lesion is sharply defined at the margin, being apparently encapsuled by fibrous tissue. The nipple is retracted, owing to involvement of the deeper parts of the galactophorous ducts.

His'rorogy.-The solid white masses which project into all the cysts are composed of active, cellular, adeno-papillomatous tissue, with abundant evidence of malignancy in the form of solid, spheroidal-celled carcinomatous areas here and there. The histology of the cholesterin-containing areas will be described in conjunction with those of Case 2.

AfTkR-History,- The patient, now in her 80th year, was visited a few weeks ago, seventeen years after the operation. She was found to be in good health, with a well-healed linear scar over the left side of the chest.

Case 2.-(1908.)

Crinicarefistory.-The patient was a married woman, age 60, who had borne no children. She first began to have pain in the left breast at the age of 34 , and this, together with an intermittent serous or blood-stained discharge from the nipple, continued for about seven years. The discharge then ceased, and for the ensuing nineteen or twenty years there was a slowly progressive enlargement of the affected organ. Iuring this time the general health remained good but in the summer of 190: she began to be alarmed lest she might be suffering from cancer, and in consequence became worried and ill. She finally consulted her doctor in November of the same year, and a diagnosis of cystic tumour, probably non-malignant, was made. The breast was amputated on November 7,1903 , and she made an excellent recovery.

Description of Specimen (Fig. 29).-The breast is very greatly enlarged, and is occupied by two large cysts with an intervening small one. These measure roughly 6 in. $\times 6$ in., 4 in. $\times 2$ in., and 11 in. $\times \frac{1}{2}$ in. Each cyst presents a rough lining, and the largest shows a number of slightly raised, glistening white nodules of cholesterin deposit. The cyst walls are much thickened, of a dark-brown colour, and speckled all over the cut surface with small glistening deposits of cholesterin crystals. There are no papillomatous in-growths like those seen in Case 1 , and no normal breast tissue can be determined. The skin of the breast is strctched out over the cysts, and the nipple is flattened out rather than retracted.

Historogy.-The microscopic structure of the walls of the cysts is very similar to that of the brown, cholesterincontaining areas in Case 1 , and the same description will serve for both.

Altrin-history.- The patient is now 76 years old, and in good health. There is a linear cicatrix at the site of the old operation. 


\section{MASSIVE CHOLESTERIN DEPOSITS IN BREAST}

\section{MICROSCOPIC STRUCTURE OF THE ChOLESTERIN-BEARING AREAS.}

In paraffin sections the salient feature of the microscopic structure of these areas is the enormous aggregation of 'cholesterin elefts - that is, spaces from which tabular crystals of cholesterin have been dissolved out in the process of paraffin embedding. In C'ase 2 these are arranged in groups, of which the individual clefts, lying parallel to one another, are often not clearly differentiated (Fig. 30). The different groups show similar orientation in certain fields only. In Case 1 the clefts are much more sharply defined. and, while still remaining roughly parallel, have assumed a curious pennate arrangement, with nothing like the same separation into distinct groups (Fig. 31). In both cases, but especially in Case 2, the fibrocellular stroma separating the groups of clefts contains large numbers of foreign-body giant cells. They lie in close relation to the clefts, which are in fact largely separated from one another by their fine cytoplasmic prolongations. In some fields large masses of clefts appear to be embedded simply in homogeneous necrotic material or granular débris,

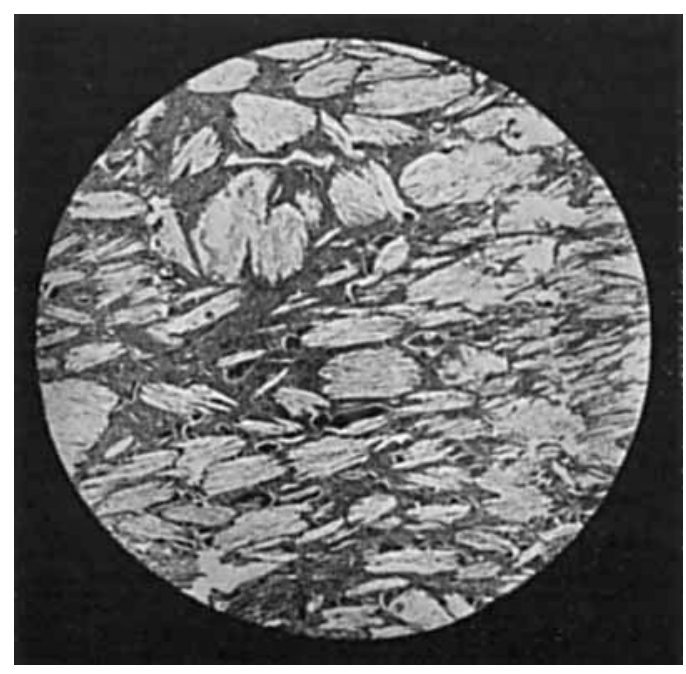

FIG. 30.--Case 2. (Tow poser.) Sote arrangement of clefts iu groups. Large foreign-body riant cells are seen in the mat rix. often with a large number of red blood-corpuscles in the stroma, or free in the clefts. Elsewhere the septa between the clefts are composed of flattened nucleated cells, probably of endothelial origin, and here again many effused red cells may be present.

The stroma also contains varying numbers of large endothelial cells with foamy cyto-

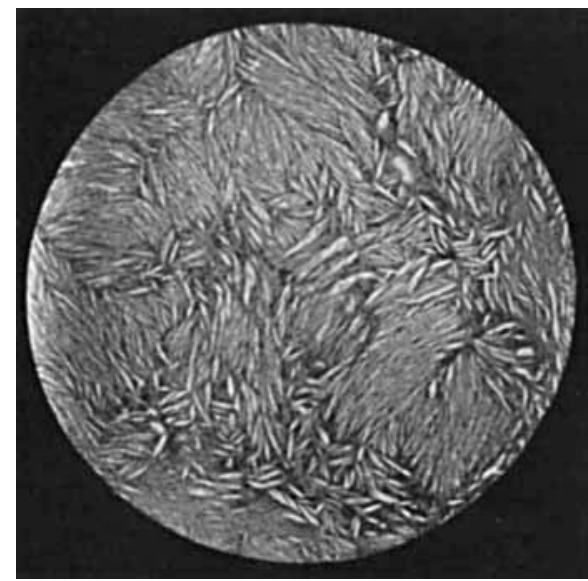

FIt, 31.-Case 1. (Low nower.) Innumerable cholcsterin clefts are seen, arranged in a somewhit pennate fashion. plasm, especially at the periphery of the cholesterin-bearing areas (Fig. 32), where they occur in large masses. Many of these cells contain granules of yellowish pigment, some of which give the Prussian-blue reaction. In certain areas the clefts arc fewer in number and more discrete (Fig. 32), and foreign-body giant cells and foamy cells are then seen in greater profusion. The cholesterin-bearing areas are bounded at the margin by a more or less definite wall of dense fibrous tissue, here and there by cellular granulation tissuc.

In frozen sections the masses and groups of tabular cholesterin crystals are very conspicuous, and their optical activity is demonstrated by the use of the polarizing microscope. They give the characteristic microchemical reactions of cholesterin, assuming a rose-pink colour when strong sulphuric acid is run under the cover-slip, and a violet colour, followed by green, and finally black, on the subsequent application of Lugol's iodine. In sections stained with scarlet-R, the foamy cells of the stroma are secn to 
be filled with orange-coloured granules and globules, while they take on a violet tint with Nile-blue sulphate-A. In association with them are numerous fine acicular crystals, apparently mainly extracellular, but also in part intracellular, which are also optically active. Exposure to temperatures up to $100^{\circ} \mathrm{C}$. has no effect on the large tabular variety (i.e., more or less pure cholesterin), but the acicular crystals are

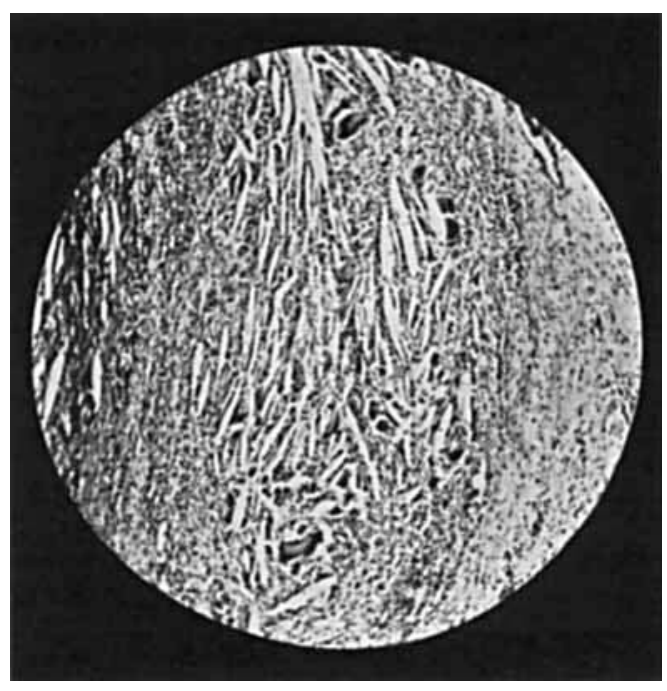

FIT. 32.-Case 1. (Low powes.) Marginal zone of cholesterin deposit, showing lange foreign-body siant cells. The pale area to the right of the field is extenkively infiltrated by foamy cells. dissolved, mainly at temperatures below $60^{\circ}$. On cooling they assume the form of anisotropic globules (fluid crystals), and are doubtless either compounds or loose combinations of cholesterin and fatty acids. It is found that exposure to $100^{\circ} \mathrm{C}$. causes the liquefied crystals to flow together, and so to form, on cooling, anisotropic globules of much larger size than if the section had been heated to $60^{\circ} \mathrm{C}$. only.

\section{OBSERVATIONS.}

The condition here described, of the deposition in the breast of very large amounts of platc cholesterin, is doubtless merely an exaggeration of a process already familiar. The causative factors at work are some of those usually associated with such deposition, viz., the accumulation in situ of necrotic tissue, effused blood, glandular secretion, and inflammatory exudate. In the process of disintegration of these substances the more soluble constituents are absorbed, while the less soluble, such as cholesterin and the hæmatogenous pigments, remain in the tissues.

The original lesion in both instances was undoubtedly a mastitis, probably subacute, with acute exacerbations, and in both the condition was of very long standing. In Case 1 the affected breast had been the seat of an acute suppurative mastitis thirty-five years previously, but this apparently healed up, and the actual duration of symptoms prior to operation was ten years. There was a slowly-growing mass in the breast, and an intermittent discharge of blood and pus from the nipple. In Case 2 the duration of symptoms was no less than twenty-seven years : during the first seven years an intermittent serous or bloody discharge from the nipple, and then a slowly progressive enlargement of the affected breast for about twenty years.

The chief factor accounting for the large size of the cholesterin deposits is obviously the long continuance of the pathological processes concerned. An intermittent discharge of serous or purulent material from the nipple probably implies some degree of intermittent retention of these exudates in the intervals, and this continued for ten years and seven years respectively in the two cases. In Case 2, where there is enormous cystic distention with very abundant deposition of cholesterin in the walls, there is also a history of gradual swelling of the breast for twenty years after the discharge from the nipple had ceased.

That there must have been a great deal of hæmorrhagic extravasation into the lesions, probably also intermittent, is shown by the presence of large amounts of hamatogenous pigment as well as of recently-effused blood. 


\section{MASSIVE CHOLESTERIN DEPOSITS IN BREAST 63}

\section{SUMMARY.}

1. The cases described are instances of long-standing subacute mastitis where, owing to retention of necrotic débris, inflammatory exudate, glandular secretion, and effused blood over long periods, very extensive deposition of crystalline cholesterin has taken place.

?. The histological appearances in paraffin sections are most striking and characteristic, consisting of an enormous number of clefts, lying parallel to one another in large groups, or arranged in a pennate fashion. The crystals occupying these clefts have the optical and microchemical characteristics of cholesterin. The intervening stroma contains forcign-body giant cells in large numbers, and many 'foamy' endothelial cells, especially round the periphery of the main deposits. The foany-cell areas contain in addition a large amount of acicular crystalline material which melts at temperatures well below $100^{\circ}($. , and which forms anisotropic globules on cooling (i.e., conpounds or combinations of cholesterin and fatty acids).

\section{REFERENCES.}

M. J. Stewart, " On the Cellular Reactions indiced by Local Deposits of Cholesterin in the Tissues:" Jour. Path. and Bact., 1915, xix, 305.

J. G. AdAm and I. Aschoff, " On the Myelins, Myelin bodies, and Potential Fluid Crystals of the Organism," Proc. Roy. Soc., London, Series B, 1906, lxxvii, 359

C. Powell Write, "Cholesterol, Fluid Crystals, and Myelin Forms," Med. Chron, 1908, xIvii, 403.

C. Powel. White, "On the Occurrence of Crystals in Tumours," Jour. Path. and Bact., 1909 , xiii, 3. 